\title{
REPRESENTAÇÃO DOS TRABALHADORES TERCEIRIZADOS EM FACE DA AMPLIAÇÃO DA PERMISSÃO JURÍDICA DA TERCEIRIZAÇÃO NO BRASIL: ANÁLISE NA PERSPECTIVA DO TRABALHO DECENTE E DE SEU IMPERATIVO DE PROTEÇÃO DOS DIREITOS HUMANOS
}

\author{
REPRESENTATION OF OUTSOURCED WORKERS IN FACE OF THE \\ ENLARGEMENT OF THE LEGAL PERMISSION OF OUTSOURCING IN \\ BRAZIL: AN ANALYSIS BY THE PERSPECTIVE OF DECENT WORK \\ AND ITS IMPERATIVE FOR THE PROTECTION OF HUMAN RIGHTS
}

\author{
Silvio Beltramelli Neto \\ Pontifícia Universidade Católica de Campinas - PUC/Campinas - (Campinas, SP, Brasil) \\ Laís Silveira \\ Pontifícia Universidade Católica de Campinas - PUC/Campinas - (Campinas, SP, Brasil)
}

Recebimento: 2 out. 2018

Aceitação: 18 mar. 2019

\begin{abstract}
Como citar este artigo / How to cite this article (informe a data atual de acesso / inform the current date of access):
BELTRAMELLI NETO, Silvio; SILVEIRA, Laís. Representação dos trabalhadores terceirizados em face da ampliação da permissão jurídica da terceirização no Brasil: análise na perspectiva do trabalho decente e de seu imperativo de proteção dos direitos humanos. Revista da Faculdade de Direito UFPR, Curitiba, PR, Brasil, v. 64, n. 1, p. 39-61, jan./abr. 2019. ISSN 2236-7284. Disponível em: <https://revistas.ufpr.br/direito/article/view/61985>. Acesso em: 30 abr. 2019. DOI: http://dx.doi.org/10.5380/rfdufpr.v64i1.61985.
\end{abstract}

\section{RESUMO}

A propósito do recente advento da Lei da Terceirização (Lei 13.429/2017) e da Lei da Reforma Trabalhista (Lei 13.467/2017), o presente artigo propõe uma reflexão crítica acerca dessa nova legislação, a partir da percepção de uma crise global e nacional da representatividade sindical aplicada à problemática da representação sindical dos trabalhadores terceirizados e sob a perspectiva da proteção dos direitos humanos dos trabalhadores, em especial do objetivo estratégico da proteção dos direitos fundamentais nas relações de trabalho, que compõe a concepção de trabalho decente segundo a Organização Internacional do Trabalho. Para tanto, foram empregados os métodos hipotéticodedutivo de abordagem e bibliográfico de procedimento. Conclui-se pela situação de desamparo dos trabalhadores ante as óticas jurídica, econômica e sindical, devido à ampliação das permissões jurídicas da terceirização, implicando o agravamento da crise sindical, a supressão de direitos laborais e a precarização das condições de trabalho de um dos segmentos mais frágeis da massa de pessoas que vivem da venda da força de trabalho.

PALAVRAS-CHAVE

Direitos humanos. Trabalho decente. Terceirização. Reforma trabalhista. Representação sindical.

\section{ABSTRACT}

Regarding the recent advent of the Outsourcing Law (Law 13.429/2017) and the Labor Legislation Reform (Law 13.467/2017), the present article introduces a critical reflection about this new legislation, guided by the perception of an existing global and national crisis of the trade union 
representativeness applied to the specific problem of the trade union representation of outsourced workers and by the perspective of the protection of the labor human rights, notably through the strategic objective of the protection of fundamental rights in labor relations, which makes up the concept of decent work, according to the International Labor Organization. For this purpose, the hypothetico-deductive method and the bibliographic procedure were applied. It is concluded that there is a situation of helplessness of the workers from a juridical, economic and trade union perspective, due to the expansion of the legal permission of outsourcing practices, resulting in an increase of trade union crisis, suppression of labor rights and precarious working conditions for one of the most fragile segments of the mass of people living from the sale of their labor power.

\section{KEYWORDS}

Human rights. Decent work. Outsourcing. Labor reform. Union representation.

\section{INTRODUÇÃO}

A partir da premissa de que a proteção dos direitos humanos dos trabalhadores é ínsita à concepção de trabalho decente apresentada pela Organização Internacional do Trabalho (OIT), o presente artigo tem por escopo problematizar, na perspectiva das condições laborais dos trabalhadores terceirizados e da realidade da atuação sindical brasileira, o caminho adotado pelo Brasil, a partir da sensível alteração jurídica produzida pela Lei 13.429, publicada em 31 de março de 2017, que ampliou, substancialmente, as hipóteses de terceirização de atividades, em comparação com os padrões jurídicos vigentes à época de sua aprovação.

Desde sua contextualização como fenômeno global, apresentar-se-á o itinerário fático e jurídico da terceirização no Brasil até o momento atual, para, a seguir, projetar as mudanças legislativas alusivas à terceirização e à negociação coletiva para o campo sindical, partindo da configuração do sistema jurídico brasileiro de representação de trabalhadores para então oferecer, sem intento determinista, uma reflexão crítica sobre pontos sensíveis em termos de condições de trabalho e direitos para o trabalhador terceirizado em cotejo com o imperativo de proteção dos direitos humanos laborais, consagrado pela concepção internacional de trabalho decente.

Para este trabalho foram empregados os métodos hipotético-dedutivo de abordagem e bibliográfico de procedimento.

\section{O DEVER ESTATAL DE PROTEÇÃO DOS DIREITOS HUMANOS COMO OBJETIVO ESTRATÉGICO DA CONCEPÇÃO DE TRABALHO DECENTE}

A OIT, em 1999, como nova estratégia de atuação frente às alterações econômicas e sociais ocorridas no final do século XX, lançou a concepção de trabalho decente como eixo temático central de suas atividades (CRIVELLI, 2010, p. 90-153), afirmando-o como o "ponto de convergência de 
seus quatro objetivos estratégicos”, quais sejam, a promoção dos direitos fundamentais no trabalho, o emprego, a proteção social e o diálogo social (OIT, 1999, p. 6).

Interessa, neste momento, notar que o primeiro objetivo estratégico foi dividido em três prioridades, quais sejam, promover a Declaração da OIT sobre Princípios e Direitos Fundamentais no Trabalho, de 1998, intensificar a luta contra o trabalho infantil e, finalmente, renovar as atividades relativas às normas da OIT, todas com o desígnio de preservar os princípios e direitos do trabalho. Proteger os direitos humanos ("fundamentais”) do trabalhador, portanto, é um imperativo conceitual da ideia de trabalho decente, assim como se reconhece à própria razão de existir da OIT.

Segundo J. J. Gomes Canotilho (2003, p. 407-410), os direitos humanos desempenham quatro funções fundamentais: função de defesa ou de liberdade, função de prestação social, função de proteção perante terceiros e função de não discriminação.

A função de defesa ou de liberdade visa pôr a salvo da arbitrariedade do Estado os interesses do cidadão, ensejando a abstenção estatal de intervenção em face de determinados direitos. A função de prestação social remete à concretização dos direitos humanos cuja fruição exige providências do Estado, v.g., saúde, educação e segurança.

A função da proteção perante terceiros demanda providências estatais voltadas à proteção dos titulares de direitos humanos em face da violação perpetrada por outros particulares (ação de proteger para evitar a violação). Tal função insta os diferentes órgãos estatais a prevenir e reprimir afrontas a direitos humanos, mediante providências políticas públicas, edição de leis punitivas e realização de investigações, julgamentos e imposição de sanções.

A função de não discriminação deriva da igualdade como pilar da salvaguarda da dignidade da pessoa humana e impõe o tratamento estatal de seus cidadãos como iguais, em todas as suas instâncias de atuação.

Com inspiração nesta classificação, é possível afirmar que todo direito humano está apto a ensejar dever de respeito, promoção e proteção, a ser desincumbido, em qualquer caso, com observância do imperativo de proibição da discriminação ${ }^{1}$, ao que estão adstritas todas as instâncias estatais (administrativas, legislativas e judiciárias) (BELTRAMELLI NETO, 2018, p. 45).

Sob esta ótica, a proteção dos direitos humanos dos trabalhadores como cerne do trabalho decente afigura-se evidente manifestação do dever estatal de proteção daqueles direitos, ao qual está

\footnotetext{
${ }^{1} \mathrm{O}$ triplo ônus de respeito, proteção e promoção consubstancia obrigação jurídica corriqueiramente enunciada em tratados de Direito Internacional dos Direitos Humanos, como se pode inferir, v.g., do artigo $2^{\circ}$ do Pacto Internacional de Direitos Civis e Políticos, do artigo $2^{\circ}$ do Pacto Internacional de Direitos Econômicos, Sociais e Culturais (ONU) e dos artigos $1^{\circ}$ e $2^{\circ}$ da Convenção Americana Sobre Direitos Humanos (OEA). Todos os citados tratados são documentos em vigor e regularmente ratificados pelo Brasil.
} 
adstrito o Estado brasileiro (incluindo seus legisladores), enquanto membro da OIT. Eis, pois, a premissa que inspira a análise que a seguir será desenvolvida.

\section{TERCEIRIZAÇÃO: FENÔMENO TOYOTISTA DO CAPITALISMO DE ACUMULAÇÃO FLEXÍVEL}

A terceirização é técnica de organização do trabalho, dentro do processo produtivo, cujo uso difundido levou a que o Direito dela se ocupasse.

A “entrega” de parte do processo produtivo a outrem, mediante subcontratação, afirma-se no contexto da transição do capitalismo de superacumulação para o capitalismo de acumulação flexível, vivenciada na segunda metade do século XX e que pautou, no campo das relações laborais, outra transição, a do sistema fordista de organização do trabalho ${ }^{2}$ para o sistema toyotista, ambas essas passagens inspiradas pelo intuito de superação da rigidez pela fluidez de capitais, da produção (just-in-time) e da mão de obra, nesse último caso com redução do número de trabalhadores centrais (HARVEY, 2004, p. 140-144). Passa a ter lugar a era dos "trabalhadores hifenizados", assim chamados por Huw Beynon: part-time workers (trabalhadores em tempo parcial), temporary-workers (trabalhadores temporários), casual-workers (trabalhadores casuais), self-employed workers (trabalhadores autônomos), etc. (ANTUNES, 1999, p. 72).

O toyotismo é considerado produto de quatro fases de profundas mudanças na organização do trabalho das indústrias japonesas, a partir da crise do capitalismo de superacumulação (ANTUNES, 2003, p. 31-32). A primeira fase remonta ao emprego, pela indústria automobilística japonesa, de técnicas produtivas da indústria têxtil, notadamente a exigência da operação de várias máquinas pelo empregado. A segunda fase consiste no desenvolvimento de práticas de aumento de produção, sem aumento do quadro de funcionários, como resposta à crise financeira japonesa pós- $2^{\mathrm{a}}$ Guerra Mundial. A terceira fase alude à importação da concepção de reposição de mercadoria conforme o consumo (just-in-time), difundida nos supermercados dos EUA. E a quarta fase consistiu na expansão do kanban (versão japonesa do just-in-time) às empresas subcontratadas e fornecedores.

Este modelo japonês acabou por preconizar o avanço tecnológico, a capacidade de extração intensificada do trabalho, o trabalho em equipe, o controle sindical e o ganho salarial de acordo com a produtividade.

\footnotetext{
${ }^{2}$ O sistema fordista é caracterizado pela produção massificada, organizada em linha de montagem, com controle de tempos e movimentos (produção em série cronometrada) e fragmentação de tarefas, havidos em unidades fabris concentradas e com o protagonismo de relações de subordinação verticalizadas (ANTUNES, 2003, p. 25).
} 
No que tange à terceirização, a partir da experiência italiana de descentralização produtiva, fala-se no advento da "especialização flexível” - consequência da aplicação dos cânones da acumulação flexível do capital aos processos produtivos -, que articula, de um lado, significativo desenvolvimento tecnológico e, de outro, desconcentração produtiva, com delegação para pequenas e médias empresas (ANTUNES, 2003, p. 25).

Enquanto fenômeno mundial, a implantação da terceirização como método de organização do trabalho atende e viabiliza, no campo das relações laborais, as expectativas do capitalismo de acumulação flexível, o qual, por sua vez, também se materializa na seara política, pela via do neoliberalismo, que implanta agenda própria de medidas relacionadas à questão jurídica da terceirização. Preceitua a agenda neoliberal, entre outros tópicos, a intensa desregulamentação e flexibilização das relações de trabalho e a coibição enérgica da atuação sindical (ANTUNES, 1999, p. 66).

É crucial destacar para os fins deste trabalho que a terceirização é técnica toyotista que também cumpre a função política de confrontar e enfraquecer o sindicalismo forjado pela consciência de classe favorecida pelo sistema de concentração de mão de obra nas fábricas, algo sobremaneira diluído pelas práticas pertinentes à terceirização (HARVEY, 2004, p. 145). Com a terceirização, consolida-se uma nefasta distinção entre trabalhadores de primeira categoria (contratados diretamente) e de segunda categoria (terceirizados), que dissolve a identidade de classe, minando o alicerce do sindicalismo combativo (DRUCK, 2001, p. 97). Não por outro motivo, o toyotismo, no Japão, também se justificou pela necessidade de enfrentamento de um confrontante sindicalismo japonês, que viria, depois da intervenção toyotista, a se tornar submisso ao patronato (ANTUNES, 1999, p. 32-33).

\section{TERCEIRIZAÇÃO NO BRASIL ENQUANTO FENÔMENO SOCIAL}

Quanto ao Brasil, é possível periodizar a implementação do toyotismo em três fases (DRUCK, 2001, p. 102-103). A primeira, vivenciada na passagem da década de 70 à de 80 , corresponde à adoção dos “Círculos de Controle de Qualidade”. A segunda, compreendida entre meados da década de 80 e de 90, testemunhou a implementação, pela indústria automobilística brasileira, de práticas como a produção just-in-time, os Programas de Qualidade Total e o Controle 
Estatístico de Processo. E, por fim, a terceira, da década de 90 em diante, caracterizou-se pela expansão ao setor de bens e serviços da cultura da qualidade.

O ideário toyotista encontrou eco na necessidade brasileira da busca de novos padrões de organização do trabalho, escancarada nos anos 90, em razão, de um lado, da exigência, imposta pelo mercado aberto e internacionalmente competitivo, de redução de custos, com maiores produtividade e qualidade e, por outro, da sobrevivência do setor produtivo em um país marcado pela instabilidade econômica e pelo processo inflacionário crônico (DRUCK, 2001, p. 118). Todavia, não se pode afirmar que houve integral disseminação do toyotismo no Brasil, seja porque ainda permanece com segmentos produtivos usuários de técnicas fordistas, seja porque a implementação das práticas toyotistas ainda esbarra em uma cultura marcadamente autoritária, pela qual os trabalhadores são impingidos a aceitar as novas exigências da rotina de trabalho pela ameaça do desemprego, em vez de serem convencidos a assumi-las na crença da melhoria de suas condições laborais (DRUCK, 2001, p. 115$)^{3}$.

As idiossincrasias brasileiras em face do modelo japonês de flexibilização do trabalho fizeram nascer, na seara industrial, duas vertentes de radicalização de tal modelo atinentes à terceirização, denominadas consórcio modular e condomínio industrial, que se diferem em relação à localização dos prestadores, os quais, no consórcio modular, encontram-se na mesma planta da montadora e, no condomínio industrial, acham-se no interior da empresa principal ou em suas proximidades. Outro fator que os distingue consiste no fato de, no condomínio industrial, a empresa principal ser encarregada da montagem final de seu produto, ao passo que, no consórcio, é responsável pela elaboração do projeto, verificação da qualidade final e marketing do produto (ALFARO, 2016, p. 27-28).

Segundo o Departamento Intersindical de Estatística e Estudos Socioeconômicos (DIEESE), a análise qualificada de informações constantes de bancos de dados oficiais do Governo, notadamente o Cadastro Nacional de Informações Sociais (CNIS), a Relação Anual de Informações Sociais (Rais) e a Classificação Nacional de Atividades Econômicas (CNAE), permite identificar as principais atividades econômicas que são, tipicamente, objeto de terceirização, entre elas: manutenção e reparação, representação comercial, suporte técnico, fornecimento e gestão de recursos humanos para terceiros, atividades de monitoramento, atividades de cobrança, construção civil, confecção de

\footnotetext{
${ }^{3}$ A superação desta barreira vem sendo buscada pela aplicação de outro instituto tipicamente toyotista, denominado endomarketing, calcado em sistemas de promoção interna dos trabalhadores e na participação nos lucros e resultados, visando também proporcionar o desenvolvimento de novas ideias e, por conseguinte, o crescimento da eficiência produtiva (ALFARO, 2016, p. 25).
} 
roupas, fabricação de calçados, coleta de resíduos, consultoria em tecnologia da informação, atividade de teleatendimento e serviços de engenharia (DIEESE, 2017a, p. 3).

Em números absolutos, em 2014, havia 12,5 milhões de empregados em atividades tipicamente terceirizadas e 35,6 milhões nas tipicamente contratantes (contratação direta, sem intermediação), ou seja, aquelas respondem por cerca de um quarto dos vínculos de trabalho formais no Brasil. No final de 2014, verifica-se, entre os contratados diretamente, que, de cada 100 vínculos ativos, pouco mais de 40 foram rompidos. Já nos setores tipicamente terceirizados, essa relação é de 100 vínculos ativos para 80 rompidos, indicando que as atividades tipicamente terceirizadas sofrem alta rotatividade - os vínculos nas atividades tipicamente terceirizadas duram, em média, dois anos e 10 meses, enquanto que os contratos diretos duram, em média, cinco anos e 10 meses (DIEESE, 2017a, p. 4-7)

A remuneração nominal média, nas atividades tipicamente terceirizadas, também é consideravelmente inferior à verificada para os vínculos diretos, a saber: em dezembro de 2014, a remuneração média nos contratos diretos era de $\mathrm{R} \$ 2.639,00$, enquanto nas atividades tipicamente terceirizadas era de R\$2.021,00. O porte do empregador também acirra este distanciamento. Nas empresas que mantêm entre um e quatro e entre cinco e nove empregados, nas atividades tipicamente terceirizadas, a diferença salarial média a bem das empresas de mesmo porte que efetuam contratação direta é de 14,5\% e 5,1\%, respectivamente. Diferentemente, naquelas com 1.000 ou mais empregados, a diferença salarial média em prol das empresas que contratam diretamente chega a 47,6\% (DIEESE, 2017a, p. 19).

A disparidade em desfavor dos trabalhadores terceirizados permanece quando os assuntos são jornada de trabalho e acidente de trabalho. Tem-se que 85,9\% dos terceirizados cumprem jornada contratada na faixa de 41 a 44 horas semanais contra 61,6\% nas atividades tipicamente contratantes (DIEESE, 2017a, p. 13). Consoante estudo da Central Única dos Trabalhadores (CUT), igualmente baseado em dados governamentais oficiais, é possível afirmar que trabalhadores terceirizados, no Brasil, laboram cerca de três horas a mais, semanalmente, em comparação com contratados diretos, sem considerar horas extras ou banco de horas realizadas (CENTRAL ÚNICA DOS TRABALHADORES, 2014, p. 14). De outra banda, na faixa de remunerados até 1,3 salário mínimo, há mais acidentes de trabalho típicos nas atividades tipicamente terceirizadas em comparação com as

\footnotetext{
4 “Em certos casos (terceirização interna), ela reaproveita uma parte dos trabalhadores expulsos, valendo-se de outra empresa, que os comercializa. Em geral eles voltam com um uniforme mais simples, um salário mais pobre e uma aderência menor. E ela também os reencontra diferente, sem o status e os ônus de empregadora. É como uma espécie de mágica” (VIANA, 2003, p. 216).
} 
atividades desempenhadas em contratação direta, chegando a ser duas vezes mais alta, em alguns casos (DIEESE, 2017a, p. 17).

\section{TERCEIRIZAÇÃO NO BRASIL ENQUANTO FENÔMENO JURÍDICO}

A trajetória da legislação brasileira afeta ao tema evidencia a já referida ligação da terceirização com o capitalismo de acumulação flexível e com a agenda neoliberal, contudo não sem atropelos.

É que a história do direito do trabalho (e, no Brasil, não é diferente) remete à regulação de uma relação fática essencial e naturalmente bilateral, entre dono dos meios de produção e detentor da força de trabalho. Traduzida juridicamente, essa relação formaliza-se mediante um contrato entre duas partes: de um lado, quem contrata, remunera e se beneficia da atividade laboral desempenhada e, de outro, quem dispõe dessa atividade em troca de remuneração. A terceirização, do ponto de vista prático, insere um terceiro personagem (o prestador de serviços) sem, contudo, alterar o panorama entre quem se beneficia, diretamente, do serviço prestado e de quem o presta de fato. O intermediário apenas experimenta a vantagem econômica pela facilitação da flexibilização da relação entre os atores essenciais do enlace laboral, em termos de tempo e encargos (jurídicos e financeiros).

Em sendo assim, a legislação trabalhista brasileira, construída a partir da bilateralidade do contrato de trabalho, tem na regulação da terceirização um desafio a essa clássica fórmula hegemônica (DELGADO, 2016, p. 487), consagrada nos artigos $2^{\circ}$ e $3^{\circ}$ da Consolidação das Leis do Trabalho (CLT).

A primeira norma brasileira relacionada à terceirização advém da década de 40 , com a promulgação da própria CLT e seu artigo 455, permissivo da realização de subcontratação de empregados na área da construção civil (SOUZA; LEMOS, 2016, p. 9).

Seguiu-se com a edição do Decreto-Lei 200/67, autorizador da ampla descentralização da execução das atividades da Administração Pública Federal, complementado pela Lei 564/70, que apresentou um rol exemplificativo dessas atividades passíveis de terceirização, quais sejam, “transporte, conservação, custódia, operação de elevadores, limpeza e outras assemelhadas”.

Após, editou-se a Lei 6.019/74 (“Lei do Trabalhador Temporário”), que permitiu que as empresas contratassem mão de obra de menor custo e por tempo determinado sem, no entanto, assumir qualquer direta responsabilidade em relação ao trabalhador, vinculado a uma empresa interposta especialmente constituída para o fim deste tipo de intermediação. Posteriormente, novas 
normas ampliaram a tolerância jurídica à terceirização, como a Lei 7.102/83 (“Lei sobre os Serviços de Vigilância”).

No ano 1994, lei federal inseriu na CLT o parágrafo único do artigo 442, declarando a inexistência de vínculo de emprego entre os associados de uma sociedade cooperativa e o tomador de serviços dessa, dando ensejo a uma onda de delegação de atividades produtivas a cooperativas, posteriormente arrefecida por uma avalanche de decisões judiciais declaratórias de nulidade de contratos mantidos com esta roupagem, em fraudulenta ocultação de verdadeiro vínculo de emprego entre contratante e pseudocooperado.

A existência de fragmentos legislativos acerca da terceirização frente à sua disseminação prática e as frequentes demandas jurídicas advindas desse quadro levou a que o Poder Judiciário, mais especificamente a Justiça do Trabalho, fosse chamado a estipular os parâmetros jurídicos da terceirização, e o fez, inicialmente, nos anos 80, pela aprovação da Súmula de Jurisprudência n 256 , entendimento consolidado do Tribunal Superior do Trabalho (TST - órgão de cúpula da Justiça do Trabalho brasileira), de cuja revisão posterior originou-se a Súmula nº 331.

Em síntese, a Súmula no 331, partindo do rechaço à terceirização como mera intermediação de mão de obra, estabelece uma distinção entre objetos passíveis e impassíveis de serem terceirizados, enumerando os primeiros, admitidos desde que inexistente a pessoalidade e a subordinação. São eles: vigilância, conservação e limpeza e serviços especializados ligados à atividade-meio do tomador (concepção desde sempre suscitadora de intensa controvérsia sobre sua configuração, no plano dos fatos). A mesma súmula fixa a responsabilidade subsidiária do tomador de serviços pelo inadimplemento das obrigações trabalhistas pelo empregador prestador de serviços.

Até março de 2017, a Súmula nº 331 do TST foi o referencial jurídico de regulação da terceirização no Brasil, panorama que se alterou com a aprovação da Lei 13.429, de 31 de março de 2017, (“Lei da Terceirização”) e, meses depois, da Lei 13.467/2017 (“Lei da Reforma Trabalhista”). Além dessas citadas leis de 2017, a referida súmula, no mês de agosto de 2018, foi alvo de dois julgamentos do Supremo Tribunal Federal, dotados de repercussão geral, relativos à Arguição de Descumprimento de Preceito Fundamental (ADPF) nº 324 e do Recurso Extraordinário (RE) 958252, tendo sufragado o pleno do Excelso Pretório, por sete votos a quatro, a licitude da terceirização ou de qualquer outro modo de divisão do trabalho em todas as atividades das empresas, inclusive finalísticas, invalidando, por conseguinte, as diretrizes principais dispostas pela Súmula 331 do TST, em convergência com a ótica da nova legislação levada a efeito.

A Lei 13.429/2017 promoveu substancial ampliação das possibilidades de terceirização de serviços, em comparação com os padrões fixados pela já aludida legislação fragmentada e, sobretudo, 
pela Súmula $\mathrm{n}^{\circ} 331$ do TST, e o fez por força de alteração do texto de uma lei específica, qual seja, a Lei 6.019/74 (“Lei do Trabalho Temporário”), que deixa de disciplinar apenas o trabalho temporário, passando a versar sobre todos os tipos de prestação de serviços.

O novel artigo $4^{\circ}$-A da Lei $\mathrm{n}^{\circ}$ 6.019/1974 define, sob um mesmo conceito, o trabalho temporário (específico) e a prestação de serviços a terceiros (geral) como sendo “a transferência feita pela contratante da execução de quaisquer de suas atividades, inclusive sua atividade principal, à pessoa jurídica de direito privado prestadora de serviços que possua capacidade econômica compatível com a sua execução”. Percebe-se que o texto normativo, ao tolerar a transferência de qualquer atividade da empresa, inclusive a principal, fez questão de, explicitamente, abolir a distinção entre atividade-meio e atividade-fim, adotada pela Súmula $\mathrm{n}^{\circ} 331$ do TST como marco de diferenciação entre terceirização lícita e ilícita.

Segundo a versão atual da lei (artigo $2^{\circ}$ ), o trabalho temporário passa a se caracterizar como modalidade específica de terceirização, praticada por empresas especializadas apenas neste tipo de alocação de mão de obra e aceita exclusivamente para atender à substituição transitória de pessoal permanente (férias, licença-maternidade, licença para tratamento de saúde, etc.) ou à demanda complementar de serviços.

O advento do artigo 19-B excluiu da aplicação da lei em questão as empresas de vigilância e transporte de valores, que permanecem reguladas por legislação especial, e, subsidiariamente, pela CLT. A contrario sensu, depreende-se da nova disciplina a mais ampla liberdade patronal de terceirizar atividades, inclusive na área rural. Nesta linha, a redação atual do artigo $5^{\circ}$ da Lei $n^{\circ}$ 6.019/1974 autoriza a ser tomador de serviços terceirizados tanto a pessoa física quanto a jurídica, reiterando a possibilidade de delegação de "quaisquer de suas atividades, inclusive sua atividade principal”.

Para além da quase ilimitada gama de atividades passíveis de terceirização, o novo artigo 4A, parágrafo $1^{\circ}$, permite a subcontratação, pela prestadora de serviços, de outras empresas para realização dos serviços objeto da contratação junto ao tomador, admitindo a instituição de uma cadeia interminável de subcontratações (“quarteirização”) (DIEESE, 2017b).

Novas disposições contidas nos parágrafos do artigo $5^{\circ}$ da Lei $n^{0}$ 6.019/1974 ainda vedam à contratante a utilização dos trabalhadores em atividades distintas daquelas que foram objeto do contrato com a empresa prestadora de serviços, além de autorizar que os serviços contratados sejam executados nas instalações físicas da empresa tomadora ou em outro local, de comum acordo entre as partes. Fixa-se, ainda, a responsabilidade da tomadora de garantir as condições de segurança, 
higiene e salubridade dos trabalhadores terceirizados, quando o trabalho for realizado em suas dependências ou local previamente convencionado em contrato.

O $\S 4^{\circ}$ do artigo $5^{\circ}$ diz que a contratante "poderá” estender ao trabalhador da empresa de prestação de serviços o mesmo atendimento médico, ambulatorial e de refeição destinado aos seus empregados, existente nas dependências da contratante, ou local por ela designado. Chama a atenção tratar-se de providência facultativa, formalizando o tratamento desigual que permeia o trabalho terceirizado.

Ademais, a lei mantém o padrão estatuído pela Súmula nº 331 do TST ao estabelecer que a tomadora é apenas subsidiariamente responsável pelas obrigações trabalhistas e previdenciárias referentes ao período em que ocorrer a prestação de serviço, de modo que o inadimplemento da prestadora/empregadora só ensejará cobrança à tomadora quando esgotados os meios de obtenção do saldo da dívida perante a intermediadora de mão de obra, o que, em regra, como se apreende da experiência anterior à novidade legal, só acontecerá em juízo, na fase de execução de sentença condenatória; portanto, após longo período de discussão judicial.

Em complemento, a chamada "Lei da Reforma Trabalhista” (Lei 13.467/17), que procedeu a substanciais alterações da CLT em ordem também a flexibilizá-la, fez introduzir dois outros artigos na Lei $\mathrm{n}^{\circ}$ 6.019/1974, quais sejam, os artigos 5º-C e 5º-D, estabelecendo uma espécie de “quarentena”, ao vedar que empresas contratem como trabalhadores terceirizados quem tenha sido seu empregado diretamente admitido nos 18 meses subsequentes à dispensa ou demissão.

Em suma, intensificando o cumprimento da agenda neoliberal para as relações de trabalho, o Brasil, com a Lei da Terceirização, incentiva a contratação triangular e, com isso, permite que se cogite a forte ampliação do atual quadro de mais de 12 milhões de pessoas sujeitas a um regime de trabalho precarizado, porquanto deficitário, como estatisticamente demonstrado, em termos de longevidade contratual, remuneração, limitação de jornada laboral e de riscos à saúde e segurança.

Em que pese esta regulamentação mais detalhada e ampliativa da terceirização, é certo que, juridicamente, a possibilidade do reconhecimento de vínculo empregatício direto entre a tomadora de serviços e o trabalhador não deixou de existir, porquanto ainda vige o artigo $9^{\circ}$ da CLT, segundo o qual "serão nulos de pleno direito os atos praticados com o objetivo de desvirtuar, impedir ou fraudar a aplicação dos preceitos contidos na presente Consolidação”. Tal dispositivo é tido como fundamentação do afastamento judicial da triangulação típica da terceirização, nas hipóteses em que, de fato, for constatado mero fornecimento de mão de obra, que submete o trabalhador à subordinação ao tomador de serviços. 
A polêmica questão jurídica da relação triangular inerente à terceirização segue acompanhada de outro mote não menos complexo: a representação sindical do trabalhador e da trabalhadora terceirizados.

\section{BREVE ESCORÇO HISTÓRICO-NORMATIVO DA ORGANIZAÇÃO SINDICAL BRASILEIRA}

À semelhança dos sindicatos europeus, a admissão jurídica das organizações sindicais brasileiras submeteu-se a três fases, quais sejam, proibição, tolerância e reconhecimento, sendo certo que o movimento de trabalhadores, no Brasil, desencadeou-se não propriamente com a feição sindical, mas mutualista, em função da concomitância entre os sistemas de trabalho livre e escravo (MISAILIDIS, 2001, p. 43).

As primeiras formas associativas brasileiras de trabalhadores são constatadas ao final do século XIX, com atuação de perfil mais assistencialista do que reivindicatória, em que pese a proibição pela então vigente Constituição de 1824 das chamadas corporações de ofício (MISAILIDIS, 2001, p. 43-44).

Apesar dessa proibição constitucional, cerca de quatro décadas depois, observou-se o surgimento de associações de trabalhadores denominadas de ligas operárias, formadas sem restrição e que pleiteavam melhores condições de trabalho, propiciando a formação de modelos sindicais plurais (NASCIMENTO, 1989, p. 52).

Já no início do século XX, concomitantemente com o surto industrial do País, causador da concentração populacional na região sudeste do território, o movimento operário, integrado basicamente por trabalhadores estrangeiros e oriundos da área rural, conquanto ainda carente de reconhecimento legal e confrontado pela violência estatal, vê-se impulsionado por reivindicações em favor de melhores condições laborais, levadas a efeito, muitas vezes, por importantes movimentos grevistas, sobretudo nas duas primeiras décadas (MISAILIDIS, 2001, p. 45-49). À época, na maioria das indústrias que se instalaram no País, prezava-se a livre pactuação dos contratos laborais, permitindo condições desiguais entre homens, mulheres e crianças, falta de segurança no trabalho e problemas de remuneração em patamar condizente com a sobrevivência básica (MISAILIDIS, 2001, p. 27).

Decorrência desse contexto, as associações operárias adquiriram o nome de "sindicato" em seis de janeiro de 1903, com a promulgação do Decreto 979, que autorizou a reunião de profissionais da agricultura e indústria para a defesa de seus interesses. 
A partir deste marco no direito coletivo do trabalho brasileiro, observou-se a promulgação de importantes normas que inauguraram a regulação estrutural da organização sindical brasileira, sendo a primeira delas o artigo 72 da Constituição de 1891, que previu o direito de livre associação, seguida dos Decretos 979/1903 e 1.637/1907, que dispuseram sobre a permissão de criação de sindicatos e, posteriormente, a Constituição de 1934, que marcou o estabelecimento da fase de pluralismo e autonomia sindical.

Os anos trinta vão notabilizar a consolidação do reconhecimento jurídico de um movimento operário já não tanto marcado pela presença estrangeira, reconhecimento tal, porém, que se aufere sob controle rigoroso do Estado. O Decreto 19.770, de 19 de março de 1930, institui a "Lei dos Sindicatos”, que os estabelece como órgãos auxiliares do Governo e por esse autorizados a funcionar, a partir de estatutos padronizados, em duro golpe à autonomia das agremiações profissionais (MISAILIDIS, 2001, p. 50).

Com a promulgação da Constituição de 1937 e do Decreto 1.402/1939, a pluralidade sindical cede lugar à unicidade, modelo esse consagrado, depois, com a edição da CLT, em 1943, e que se perpetuou até os dias atuais, a ponto de ser reproduzido pelo artigo $8^{\circ}$ da Constituição Federal de 1988, atualmente vigente. Segundo tal modelo, é permitida a existência de apenas um sindicato patronal ou profissional para cada categoria em uma mesma base (área) territorial não inferior a um município.

Em meio ao declínio do regime ditatorial militar instaurado no País, em 1964, os anos 80 veem a emergência do chamado "novo sindicalismo" como resposta à crise econômica mundial e nacional dos anos 70, à financeirização do capital e ao avanço tecnológico nos processos produtivos já fragmentados pelas práticas toyotistas, associados à incapacidade do Estado de prover serviços públicos com qualidade. Contextualizada pelo clamor democrático que se intensificava e dele se valendo, a mobilização operária, muitas vezes à margem dos sindicatos oficiais controlados pelo Estado, renova-se em inúmeras e importantes greves do funcionalismo público e do setor industrial, sempre tendo por principal pleito a autonomia sindical (MISAILIDIS, 2001, p. 72-75), ou seja, a libertação do controle estatal, o que viria a ser em boa medida atendido pela Constituição Federal de 1988, aprovada como ato seguinte à retomada do governo do País pelos civis.

O “novo sindicalismo”, todavia, seria arrefecido às portas da década de 90 , sucumbindo à reestruturação produtiva impingida em escala global e à emergência da pragmática neoliberal e da financeirização do capital, passando de um sindicalismo de confronto para o sindicalismo negocial, em que o embate cede espaço para estratégias de parceria, negociação e incentivo aos pactos sindicais (ANTUNES, 2015, p. 511-512). 
Com a nova Carta Constitucional, os sindicatos brasileiros deixam de depender de autorização estatal para sua criação, contudo, seus atos constitutivos livremente redigidos devem ser submetidos ao Ministério do Trabalho, para fins de registro e apuração da observância da unicidade territorial, que ainda se mantém, tal qual estatuída na CLT (artigo 8º I, III e VIII da Constituição Federal). Não por outro motivo, senão pela adoção da "liberdade sindical mitigada”, incompatível com a plena liberdade sindical consagrada pelo artigo $2^{\circ}$ da Convenção $n^{\circ} 87$ da OIT, é que o Brasil, até hoje, não ratificou essa que é uma das oito convenções fundamentais da Organização.

O panorama normativo brasileiro atual reconhece, portanto, os sindicatos como associações, as quais têm a função de representar trabalhadores vinculados mediante laços profissionais comuns, visando tratar de problemas coletivos das respectivas bases representadas, defendendo seus interesses, com o objetivo de auferir melhores condições de vida e labor para os trabalhadores a eles associados.

As entidades sindicais brasileiras estão, à luz do artigo 511 da CLT, adstritas à representação de categorias, que nada mais são do que grupos que pretensamente se reúnem a partir do compartilhamento de ideologias e ideias, formando, assim, uma classe com interesses convergentes (PEREIRA NETO, 2016, p. 44). Existem três espécies de categoria representadas por sindicatos, segundo o ordenamento jurídico brasileiro: a categoria profissional, a categoria econômica e a categoria diferenciada.

Com relação à categoria profissional, também denominada de categoria dos trabalhadores, segundo o artigo 511, parágrafo $2^{\circ}$, da CLT, é formada a partir da paridade das condições de vida provenientes de profissão ou trabalho em comum e em situações de emprego na mesma atividade econômica ou em atividades econômicas similares ou conexas.

Em contrapartida, a categoria econômica ou categoria dos empregadores é aquela na qual se forma um vínculo social fundado na reciprocidade de interesses econômicos entre os que realizam atividades similares, conexas ou idênticas, como dispõe o artigo 511, parágrafo $1^{\circ}$, da CLT.

$\mathrm{O}$ artigo supracitado, em seu parágrafo $3^{\circ}$, preceitua a categoria diferenciada como a classe que se forma com os empregados que exercem profissões ou funções diferenciadas, por força de um estatuto profissional especial ou em consequência de condições de vida singulares, podendo considerar como exemplo médicos, advogados, professores, economistas, entre inúmeros outros. Os trabalhadores dessa categoria não se agrupam a partir das atividades exercidas pelo empregador, mas sim pelo exercício de determinada profissão; portanto, o advogado que trabalha em um escritório, em um banco ou em uma empresa farmacêutica, será sempre representado pelo sindicato dos advogados. 
A lei brasileira não reconhece, pois, mais de um sindicato representativo da mesma categoria em uma dada base territorial (artigo 8º , II, da Constituição Federal e artigo 516 da CLT), embora 0 sindicato possa ter uma base territorial de extensão distrital, municipal, intermunicipal, estadual e interestadual, sendo que, excepcionalmente, e atendendo às peculiaridades de determinadas categorias ou profissões, o Poder Executivo, por meio do Ministério do Trabalho, poderá autorizar o reconhecimento de sindicatos com base territorial nacional (artigo 517 da CLT). O desmembramento de um sindicato é admitido, a teor do artigo 571.

O agrupamento sindical, no Brasil, portanto, submete-se a critérios rígidos: apenas um sindicato por categoria profissional ou patronal e por base territorial. Tal critério de enquadramento sindical por categorias, associado à unicidade, gera problemas práticos sérios de representatividade, pois impossibilita que os trabalhadores escolham, livremente, as associações sindicais à quais queiram se vincular.

Ademais, o sistema sindical brasileiro não se resume aos sindicatos, sendo confederativo, por apresentar diferentes graus de associações sindicais, segundo a lei. Pela ordem crescente desses graus tem-se os sindicatos propriamente ditos ( $1^{\circ}$ grau), as federações ( $2^{\circ}$ grau) e as confederações ( $3^{\circ}$ grau). As federações são organizadas por estados da Federação, a partir da reunião de um número não inferior a cinco sindicatos, desde que representem a maioria absoluta de um grupo de atividades ou profissões idênticas, similares ou conexas (artigo 534 da CLT). Já as confederações são entidades de abrangência nacional, com sede na capital do País e constituídas pelo agrupamento mínimo de três federações (artigo 535 da CLT).

Mais recentemente, as chamadas Centrais Sindicais, atuantes, desde a década de 60, na mobilização política e reivindicatória de diversas categorias profissionais, experimentaram reconhecimento jurídico pela aprovação da Lei 11.648, de 31 de março de 2008. Desvencilhadas da unicidade que vincula os três graus associativos sindicais brasileiros, as centrais sindicais estão legalmente autorizadas a coordenar a representação dos trabalhadores por meio das organizações sindicais a elas filiadas e a participar de negociações em fóruns, colegiados de órgãos públicos e demais espaços de diálogo social que possuam composição tripartite, nos quais estejam em discussão assuntos de interesse geral dos trabalhadores (artigo $1^{\circ}$ da Lei 11.648/08). Hodiernamente, as centrais sindicais se afirmaram como importantes, senão decisivas instituições de mobilização e representação sindical, no contexto brasileiro, a despeito de seu tardio reconhecimento legal.

Não obstante a existência de entidades sindicais de distintos graus, permanece o sindicato ostentando a posição de entidade de direito privado que detém o monopólio legal da representação de trabalhadores para fins de negociação coletiva e greve. 
O sistema sindical brasileiro atual, em síntese, consolida um modelo marcado pela unicidade sindical e pela compulsoriedade de representação.

\section{O IMPACTO DA LEI DA REFORMA TRABALHISTA NO PAPEL REGULADOR DA AUTONOMIA PRIVADA COLETIVA EXERCIDA PELOS SINDICATOS}

Em dezembro de 2016, foi apresentado pela Presidência da República à Câmara dos Deputados projeto de lei que tomou o número PL 6786/2016, com vistas, inicialmente, à alteração de sete artigos da CLT e outros oito da Lei n 6.019/1974 (“Lei do Trabalho Temporário”). Tal projeto tramitou naquela Casa de forma acelerada, sendo, ao final, alvo de um texto substitutivo que, surpreendentemente, propôs a modificação de mais de 100 artigos da CLT.

Com inabitual urgência à vista da importância e complexidade da matéria, o referido substitutivo foi aprovado quase que instantaneamente, na Câmara dos Deputados, no dia 26 de abril de 2017, sem que se travasse qualquer discussão sobre o texto hipertrofiado. Na sequência, identificado como PLC 38/2017, o substitutivo aprovado na Câmara foi submetido ao Senado Federal. Também carecendo de um mínimo debate sobre o seu conteúdo, e sem qualquer alteração do texto recebido da Câmara dos Deputados, foi aprovada a lei, em 11 de julho de 2017, vindo a ser sancionada no dia 13 de julho pela Presidência da República, convertendo-se na Lei nº 13.467/2017 (“Lei da Reforma Trabalhista”).

A nova lei, igualmente na esteira do ideário de flexibilização das relações e dos direitos trabalhistas, amplia sobremaneira o rol de tema afetos à relativização pela negociação coletiva entre sindicatos profissionais e sindicatos de empregadores, sem expressa vedação à mitigação de direitos nociva aos trabalhadores, instaurando o que ficou conhecido como "prevalência do negociado sobre o legislado".

O novel artigo 611-A da CLT estabelece rol exemplificativo de matérias sujeitas à negociação coletiva, entre as quais: jornada de trabalho, observados os limites constitucionais; o banco de horas anual; o intervalo intrajornada, respeitado o limite mínimo de trinta minutos para jornadas superiores a seis horas; a representação dos trabalhadores no local de trabalho; teletrabalho, regime de sobreaviso e trabalho intermitente; remuneração por produtividade, incluídas gorjetas e remuneração por desempenho individual; modalidade de registro de jornada de trabalho; troca do dia de feriado; e enquadramento do grau de insalubridade e prorrogação de jornada em locais insalubres.

Em contrapartida, o também novo artigo 611-B enuncia rol taxativo de temas infensos à negociação coletiva, podendo-se citar: salário mínimo; valor nominal do décimo terceiro salário; 
remuneração do trabalho noturno superior à do diurno; repouso semanal remunerado; remuneração do serviço extraordinário superior, no mínimo, em 50\% à do normal; férias devidas ao empregado; gozo de férias anuais remuneradas com, pelo menos, um terço a mais do que o salário normal; licençamaternidade com duração mínima de 120 dias; aviso prévio proporcional ao tempo de serviço mínimo de 30 dias; normas de saúde, higiene e segurança do trabalho previstas em lei ou em normas regulamentadoras do Ministério do Trabalho; proibição de trabalho noturno, perigoso ou insalubre a menores de 18 anos e de qualquer trabalho a menores de 16 anos, salvo na condição de aprendiz, a partir de 14 anos; medidas de proteção legal de crianças e adolescentes; entre outros já protegidos constitucionalmente.

Destarte, aos sindicatos profissionais e patronais e aos empregadores atribui-se amplo poder para regular suas relações, diferentemente do preceituado pela norma heterônoma e até mesmo para aquém do patamar por essa estabelecido, em franca dissonância com a proteção de direitos exigida pela ideia de trabalho decente.

\section{A REPRESENTAÇÃO SINDICAL DOS TRABALHADORES TERCEIRIZADOS}

No Projeto de Lei 4.330/04, precursor da Lei da Terceirização, havia previsão segundo a qual, na hipótese de o contrato de terceirização se dar entre empresa prestadora e tomadora de serviços de mesma categoria econômica, os empregados terceirizados deveriam ser representados pelo mesmo sindicato dos empregados da tomadora (BRASIL, 2004). O dispositivo não vingou e, diante do horizonte reformista imposto, constatação eloquente há que ser feita: a Lei da Terceirização simplesmente silenciou acerca da representação sindical dos trabalhadores terceirizados.

Dentro deste cenário de mais de 12 milhões de obreiros terceirizados, de enfraquecimento sindical pela ação do capitalismo de acumulação flexível e da própria terceirização, e, agora, de prevalência do negociado sobre o legislado, conjugado com o sistema sindical brasileiro pautado pela possibilidade de um único sindicato por base territorial e por categoria profissional - caracterizada essa pela similitude de condições de vida oriunda da profissão ou trabalho em comum -, afigura-se mais crucial do que nunca responder à questão sobre a qual omitiu-se a Lei da Terceirização: qual sindicato representa o trabalhador terceirizado, se essa condição não corresponde à concepção de categoria profissional tal como adotada pela lei brasileira?

A respeito, vislumbram-se dois caminhos a serem trilhados.

O primeiro aponta para que o trabalhador terceirizado seja representado pelo sindicato da categoria vinculada às atividades exercidas pelo tomador de serviços, uma vez que aquele é inserido 
no processo produtivo desse (muitas vezes em seu estabelecimento) e ali desenvolve seu cotidiano laboral (DELGADO, 2016, p. 480-481). Neste caso, em princípio, cogita-se favorecida a garantia aos terceirizados de um patamar de direitos equivalente àquele aplicável aos empregados diretamente contratados, presumivelmente melhor.

A segunda possibilidade remete a um enquadramento sindical de acordo com a atividade preponderante da empresa prestadora de serviços, ou seja, a representação formal dos terceirizados atine ao sindicato da categoria cuja atividade coaduna-se com o serviço objeto de venda pela prestadora. Essa hipótese suscita uma questão altamente controversa, pertinente à proliferação de empresas prestadoras de serviços que oferecem o desempenho de diferentes atividades em seu “portfólio”, angariando, por isso, em seu quadro funcional, profissionais que cumprem distintas funções, como vigias/porteiros, jardineiros, motoristas, faxineiros, etc., pessoas que, por certo, enfrentam dificuldade de se compreenderem como pertencentes a uma mesma categoria, em virtude da disparidade das condições de trabalho. Este fenômeno - repita-se, dissonante da ideia de "categoria profissional” consagrada pela CLT - segue acompanhado da criação de sindicatos de trabalhadores terceirizados (em sentido lato), a exemplo do Sindicato dos Empregados em Empresas de Prestação de Serviços a Terceiros, Colocação e Administração de Mão de Obra, Trabalho Temporário, Leitura de Medidores e Entrega de Avisos do Estado de São Paulo (SINDEEPRES).

Esta última vertente tem sido albergada, majoritariamente, pelos tribunais brasileiros, salvo quando há terceirização ilícita ou fraudulenta, nos termos do já citado artigo $9^{\circ}$ da CLT, hipótese em que o vínculo empregatício é declarado, judicialmente, com a tomadora de serviços e, por conseguinte, o enquadramento sindical do trabalhador se faz pelo sindicato que representa os empregados diretamente contratados por essa ${ }^{5}$.

Considerando-se que, a despeito de todas essas dúvidas jurídicas, a terceirização disseminou-se, há décadas, no Brasil e que a crescente criação de sindicatos de trabalhadores terceirizados é uma realidade, conquanto ainda há pouco aprovadas as alterações legislativas aqui analisadas, convém a avaliação da atuação recente desses sindicatos, na perspectiva da tutela dos interesses dessa população obreira. E, neste particular, o que se sabe não inspira ânimo.

O movimento sindical brasileiro, em todas as suas instâncias e graus, não logrou consenso sobre os limites da terceirização, sendo possível encontrar desde posições radicalmente contrárias até posições favoráveis entusiastas - sobretudo das agremiações cuja existência depende justamente da

\footnotetext{
5 Ilustrativamente, cf. os seguintes julgados: do Tribunal Superior do Trabalho, Recurso de Revista 932006420075180010; do Tribunal Regional do Trabalho da 1ª Região, Recurso Ordinário 00112868220135010028; e do Tribunal Regional do Trabalho da 5a Região, Recurso Ordinário 0001161-48.2012.5.05.0038.
} 
massa obreira terceirizada, como os sindicatos de trabalhadores terceirizados -, passando por entendimentos mitigados, como, por exemplo, a defesa da pertinência da terceirização de atividadesmeio (GALVÃO et al., 2017, p. 5).

Os setores mais suscetíveis à terceirização apresentam menores índices de sindicalização, se comparados aos setores mais estruturados e afeitos à contratação direta. Exemplificativamente e com base em dados de 2015, de um lado, os setores da construção civil e do comércio, marcadamente partidários da delegação de atividades, contam com índices de sindicalização de 9,3\% e 13,3\%, respectivamente; de outro lado, os ramos agrícola e da indústria de transformação, menos afeitos à terceirização, ostentam índices substancialmente superiores, de 28,7\% e 23,3\%, respectivamente. Considerando-se que a média nacional global de sindicalizados é de 19,5\%, evidencia-se o quão deficitária é a sindicalização dos terceirizados, em um país no qual o ato de se sindicalizar já é, em geral, pouco frequente (IBGE, 2017, p. 51-54).

No que se refere às negociações coletivas, é certo que quanto mais sujeita à precarização das condições de trabalho a categoria, menos mobilização sindical há e menos conquistas se concretizam em acordos ou convenções coletivas de trabalho. Para se ter uma ideia, justamente os setores mais precários em termos de condições de trabalho ostentam pouca ou nenhuma previsão, em acordo ou convenção coletiva de trabalho, sobre saúde e segurança (GALVÃO et al., 2017, p. 15).

Se assim o é para a negociação, não se pode esperar nada alentador a respeito da capacidade de realização de mobilização pelos terceirizados.

É de conhecimento geral que os posicionamentos políticos mais abrangentes da classe trabalhadora, no Brasil, são conduzidos pelas centrais sindicais, mas tampouco essas vêm sendo capazes de obter uma pauta de consenso e, ainda que dentro da pauta de cada qual, de mobilizar os sindicatos de base (GALVÃO et al., 2017, p. 5). Aliás, nem mesmo uma ação robusta contra a Lei da Reforma Trabalhista foi engendrada pelas centrais, a despeito do óbvio retrocesso impingido à proteção jurídica de todo o tipo de trabalhador (GALVÃO et al., 2017, p. 31).

Em suma, dados mostram que sindicatos de setores mais vulneráveis, como aqueles afeitos à terceirização, têm menores taxas de sindicalização, fazem menos greve e assimilam mais facilmente o discurso de modernização das relações de trabalho pela flexibilização (GALVÃO et al., 2017, p. 42).

O que se infere, portanto, do cotejo do atual panorama normativo com os dados estatísticos revela um cenário brasileiro de iminente ampliação do número de trabalhadores terceirizados nos setores mais afeitos a essa prática e, provavelmente, naqueles até o momento menos aderentes (esses motivados pelo incentivo legal), em boa medida mediante substituição de mão de obra contratada 
diretamente e, com isso, o incremento de uma massa de pessoas submetidas a uma situação de déficit do patamar de direitos e de renda em comparação com os empregados diretamente contratados. Patamar esse, aliás, ainda passível de um rebaixamento em razão da instituição da "prevalência do negociado sobre o legislado”, a ser manejada por entidades cuja representatividade sindical encontrase tomada por dúvidas jurídicas e baixíssimo poder de mobilização e de barganha.

Nesta linha, não parece alarmista a preocupação com o nível de intensificação da precarização do trabalho pela via da expansão da terceirização desmedida, apta a viabilizar um retrocesso que, no limite, permitirá indesejável e repugnante aproximação com o período histórico que antecedeu a implementação da legislação trabalhista estatal sistematizada brasileira, favorecendo, bem por isso, episódios de trabalho análogo ao de escravo, à luz de sua percepção contemporânea ${ }^{6}$.

É evidente, pois, a institucionalização por lei da possibilidade prática da renúncia de diretos ou de sua relativização a níveis de intensa vulneração.

\section{CONCLUSÃO}

A terceirização, como prática toyotista consentânea com o capitalismo de acumulação flexível globalizou-se e veio a se instalar, com vigor, no Brasil, arrebatando mais de uma dezena de milhões de trabalhadores.

O direito do trabalho brasileiro desde sempre apresentou dificuldade em lidar com os litígios envolvendo a terceirização, porquanto alicerçado na inarredável bilateralidade da relação dono de meio de produção/trabalhador. Ainda assim, encaminhamentos foram sendo dados, à miúde, pela legislação e, de modo mais abrangente, pela jurisprudência da Justiça do Trabalho brasileira, que se propôs a estabelecer limites à delegação de atividades.

Já neste contexto, como inerente ao processo de consolidação e expansão da terceirização, a consciência de classe e, com ela, a força do sindicalismo sofreram um processo de profundo enfraquecimento, que tem nos trabalhadores terceirizados, dentre aqueles classificados como detentores de empregos formais, a massa de obreiros sujeita a tratamento discriminatório em matéria de direitos e de auferimento de renda.

\footnotetext{
${ }^{6}$ A concepção contemporânea de escravidão, sobretudo consoante a avançada legislação brasileira a respeito (art. 149 do Código Penal), tem sua configuração reconhecida para muito além do cerceamento do direito de ir e vir, abrangendo aspectos ligados à dignidade da pessoa humana, a exemplo da jornada exaustiva e do meio ambiente de trabalho degradado (BELTRAMELLI NETO; ADÃO, 2017), elementos centrais, como visto, da vulnerabilidade que acomete os terceirizados.
} 
As autoridades executivas e legislativas brasileiras, aproveitando-se de um momento político e econômico recente suscetível ao aprofundamento da agenda neoliberal, ampliaram as hipóteses de terceirização para a quase ausência de limites, ao tempo em que entregam aos combalidos sindicatos a missão de enfrentar a sanha patronal pela negociação para aquém da norma estatal, em tempos de automatização, crise econômica mundial e desemprego estrutural.

Sujeitando os direitos humanos dos obreiros brasileiros a real e iminente risco de inefetividade, os legisladores brasileiros afrontaram, de modo direto, seu dever jurídico de proteção dos direitos humanos dos trabalhadores terceirizados, pilar do compromisso institucional com a promoção do trabalho decente, nos termos delineados pela OIT.

Em virtude disso, eivada de acusações de inconstitucionalidade e inconvencionalidade, as Leis da Terceirização e da Reforma Trabalhista ainda aguardam os próximos capítulos de uma batalha judicial a ser travada, sem prognósticos possíveis.

Ao trabalhador terceirizado, já inserto em uma condição holística de desamparo econômico, jurídico e sindical, diante deste quadro desalentador, só resta sonhar com a não confirmação de um futuro que se apresenta ainda mais sofrido.

\section{REFERÊNCIAS}

ALFARO, Larissa Menine. Terceirização do trabalho no Brasil, precarização e a vedação do retrocesso social. 2016. Disponível em: http://bit.ly/2Gk5Ur2. Acesso em: 12 abr. 2017.

ANTUNES, Ricardo. Adeus ao trabalho? Ensaio sobre as metamorfoses e a centralidade do mundo do trabalho. 9. ed. São Paulo: Cortez, 2003.

ANTUNES, Ricardo. Os sentidos do trabalho: ensaio sobre a afirmação e a negação do trabalho. 1. ed. São Paulo: Boitempo Editorial: 1999.

ANTUNES, Ricardo; SILVA, Jair Batista da. Para onde foram os sindicatos? Do sindicalismo de confronto ao sindicalismo negocial. Caderno CRH, Salvador, v. 28, n. 75, p. 511-527, dez/2015.

BELTRAMELLI NETO, Silvio. Direitos Humanos. 5. ed. Salvador: Juspodivm, 2018.

BELTRAMELLI NETO, Silvio; ADÃO, Felipe da Silva Pinto. Para além do ir e vir: o conceito normativo brasileiro de trabalho escravo ante o direito comparado. Revista da Faculdade de Direito UFPR, Curitiba, PR, Brasil, v. 62, n. 1, p. 113-136, maio 2017. ISSN 2236-7284. Disponível em: http://bit.ly/2GrwK1y. Acesso em: 2 out. 2018. DOI: http://dx.doi.org/10.5380/rfdufpr.v62i1.47832.

CANOTILHO, J. J. Gomes. Direito constitucional e teoria da constituição. 7. ed. Coimbra: Almedina, 2003. 
CENTRAL ÚNICA DOS TRABALHADORES. Terceirização e Desenvolvimento: uma conta que não fecha - Dossiê acerca do impacto da Terceirização sobre os trabalhadores e propostas para garantir a igualdade de direitos. São Paulo: Central Única dos Trabalhadores, 2014.

DELGADO, Mauricio Godinho. Curso de Direito do Trabalho. 15. ed. São Paulo: LTr, 2016.

DIEESE. Nota técnica no 172: terceirização e precarização das condições de trabalho - Condições de trabalho e remuneração em atividades tipicamente terceirizadas e contratantes. São Paulo: DIEESE, 2017a.

DIEESE. Nota Técnica no 175: impactos da lei 13.429/17 (antigo PL 4.302/1998) para os trabalhadores. São Paulo: DIEESE, 2017b.

DRUCK, Graça. Terceirização: (des)fordizando a fábrica - Um estudo do complexo petroquímico. São Paulo: Boitempo, 2001.

GALVÃO, Andréia et al. Movimento sindical e negociação coletiva. In: KREIN, José Dari (coord.). Reforma trabalhista: textos para discussão. Centro de Estudos Sindicais e de Economia do Trabalho, Universidade Estadual de Campinas, out/2017. Disponível em: http://bit.ly/2PdXWUh. Acesso em: 26 mar. 2018.

HARVEY, David. Condição pós-moderna. Tradução Adail Ubirajara Sobral e Maria Stela Gonçalves. 13. ed. São Paulo: Loyola, 2004.

IBGE. Aspectos das Relações de Trabalho e Sindicalização. IBGE: Rio de Janeiro, 2017.

MISAILIDIS, Mirta Lerena de. Os desafios do sindicalismo brasileiro diante das atuais tendências. São Paulo: LTr, 2001.

OIT. 87 ${ }^{\mathrm{a}}$ reúnion. Memoria Del Director General del. Trabajo decente. Genebra: Oficina Internacional del Trabajo, Ginebra, jun. 1999. Disponível em: http://bit.ly/2vb5Q7y. Acesso em: 28 set. 2018.

PEREIRA NETO, João Batista. O sistema brasileiro de unicidade sindical e compulsoriedade de representação. 2016. 269 f. Dissertação (Mestrado em Direito) - Pontifícia Universidade Católica de São Paulo, São Paulo, 2016. Disponível em: http://bit.ly/2PdYHwB. Acesso em: 12 abr. 2017.

SOUZA, Filipe Augusto Silveira de; LEMOS, Ana Heloisa da Costa. Terceirização e resistência no Brasil: o Projeto de Lei n. 4.330/04 e a ação dos atores coletivos. Cad. EBAPE.BR, Rio de Janeiro, v. 14, n. 4, p. 1.035-1.053, dez. 2016.

VIANA, Márcio Túlio. Terceirização e sindicato. Um enfoque para além do jurídico. Revista Ltr, São Paulo, ano 67, n. 7, julho de 2003. 
Desenvolvimento Econômico pelo Instituto de Economia da Universidade Estadual de Campinas - UNICAMP, integrando o Centro de Estudos Sindicais e de Economia do Trabalho - CESIT. Doutor em Direito (2013) pela Universidade de São Paulo - USP. Mestre (2007) em Direito pela Universidade Metodista de Piracicaba - UNIMEP. Especialista (2001) em Direito e Processo do Trabalho pela PUC-Campinas (2001). Graduado pela PUCCampinas em 1999. Membro do Ministério Público do Trabalho (Procurador do Trabalho). E-mail: silviobeltramelli@gmail.com

Laís Silveira

Advogada graduada pela Faculdade de Direito da PUC-Campinas. E-mail: lala_silverinha@hotmail.com 